\title{
Cl-Amidine Prevents Histone 3 Citrullination and Neutrophil Extracellular Trap Formation, and Improves Survival in a Murine Sepsis Model
}

\author{
Bethany M. Biron Chun-Shiang Chung Xian M. O'Brien Yaping Chen \\ Jonathan S. Reichner Alfred Ayala \\ Division of Surgical Research, Department of Surgery, Rhode Island Hospital, Brown University, Providence, R.I., USA
}

\section{Key Words}

Neutrophils $\cdot$ Cecal ligation and puncture $\cdot$ Inflammation .

Posttranslational modification

\begin{abstract}
Sepsis refers to the presence of a serious infection that correlates with systemic and uncontrolled immune activation. Posttranslational histone modification plays an important role in chromatin decondensation, which is regulated by citrullination. Citrullinated histone H3 (H3cit) has been identified as a component of neutrophil extracellular traps (NETs), which are released into the extracellular space as part of the neutrophil response to infection. The conversion of arginine to citrulline residues on histones is catalyzed by peptidylarginine deiminase 4 (PAD4). This study's goals were to characterize the presence of PAD4-catalyzed H3cit and NET formation during the onset of sepsis and elucidate the effects on the immune response when this mechanism of action is blocked. Adult C57BL/6 male mice were treated with $\mathrm{Cl}$-amidine, an inhibitor of PAD4, $1 \mathrm{~h}$ prior to sepsis induced by cecal ligation and puncture (CLP). Twenty-four hours after CLP, cytokine levels, H3cit protein expression, neutrophil counts, and NET production were evaluated in the peritoneal cavity. Survival studies were also performed. Here we demonstrate
\end{abstract}

that $\mathrm{Cl}$-amidine treatment prior to CLP improves overall survival in sepsis and the abrogation of PAD4 has minimal effects on the proinflammatory immune response to sepsis, while it has no effect on overall neutrophil migration to the peritoneum.

(c) 2016 S. Karger AG, Basel

\section{Introduction}

Sepsis is a life-threatening condition that elicits an exacerbated and damaging immune response with approximately 250,000 cases leading to death in the USA annually [1-3]. As of 2009, the CDC listed sepsis as the 11th leading cause of death in the USA, making sepsis a significant health care problem $[4,5]$.

Neutrophils are considered one of the most crucial components of the innate immune system during septic infection [6]. Neutrophil extracellular traps (NETs) are complex structures made of nuclear chromatin, histones, granular antimicrobial proteins, and some cytoplasmic proteins [7]. NETs are capable of physically ensnaring bacteria and facilitating the interactions between bacteria and antimicrobial effectors, ultimately leading to enhanced bacterial killing [7]. Components of NETs have

\section{KARGER}

(c) 2016 S. Karger AG, Basel

E-Mail karger@karger.com

www.karger.com/jin
Prof. Alfred Ayala

Division of Surgical Research, Department of Surgery, Rhode Island Hospital

Brown University, Aldrich 227

Providence, RI 02903 (USA)

E-Mail aayala@lifespan.org 
been shown to be elevated in septic and septic shock patients $[8,9]$, suggesting that NETs may play an important part in the innate immune response to infection [10]. However, increasing evidence has linked NET formation to various disease states, such as autoimmune diseases, as well as sepsis, suggesting that they contribute to excessive inflammation and tissue damage $[6,11,12]$.

Posttranslational histone modification plays an important role in chromatin decondensation, which is regulated by citrullination [13]. Citrullinated histone H3 (H3cit) has been identified as a component of NETs that is released into the extracellular space as part of the neutrophil response to infection [10,14-16]. Recently, it has been revealed that peptidylarginine deiminase 4 (PAD4) has a regulatory role in NET formation through mediating chromatin decondensation through hypercitrullination of the target histones $\mathrm{H} 3, \mathrm{H} 4$, and $\mathrm{H} 2 \mathrm{~A}$ [16-18]. This histone citrullination and NET formation are essential elements of host defense and have been shown to be necessary in innate immunity during bacterial infection [10].

In order to determine a putative role of NETs in sepsis, it is necessary to characterize the presence of PAD4 catalyzed $\mathrm{H} 3$ cit and NET formation during the onset of sepsis as well as the effects on the immune response when this mechanism of action is blocked. While genetic PAD4 knockout mice have been used to study the role of NETs in various disease states, including sepsis [10, 19-22], to date there is no inhibitor available that specifically targets NET formation. N-a-benzoyl-N5-(chloro-iminoethyl)$\mathrm{L}$-ornithine amide, or $\mathrm{Cl}$-amidine, is a pharmaceutical inhibitor of peptidylarginine deiminases (PADs) including PAD4 $[23,24]$. It irreversibly inactivates PADs by covalently modifying an active site cysteine that is important for its catalytic activity [23]. It was previously found to repress the formation of NET-like structures in HL-60 cells $[17,25]$, and has also been used in various studies to examine the mechanism of PAD4 and NET inhibition $[10,21,24]$.

Here we first assessed the level of $\mathrm{H} 3$ cit protein modification in a mouse cecal ligation and puncture (CLP) model of sepsis. We then suppressed H3cit in vivo using a dose of Cl-amidine prior to CLP and studied what effect this had on $\mathrm{H} 3$ cit modification as well as its effect on the immune response and overall survival. We found that $\mathrm{Cl}-$ amidine treatment prior to surgery significantly improves overall survival in a CLP model of sepsis, but it seems to have little effect on the proinflammatory or anti-inflammatory cytokine response and no effects on overall neutrophil migration to the source of infection.

\section{Materials and Methods}

Mice

C57BL/6 male mice, aged 8-12 weeks, were obtained from the Jackson Laboratory (Bar Harbor, Maine, USA) and used in all experiments. All protocols carried out with animals were done according to the NIH Guide for Animal Use and Care guidelines, and were approved by the Rhode Island Hospital Institutional animal care and use committee (AWC 0110-13).

\section{Sepsis Model Induced by CLP}

Mice were anesthetized with isoflurane and a midline incision was made in the abdomen. The cecum was isolated and ligated at a point approximately $1 \mathrm{~cm}$ from the cecal tip, punctured twice with a 22 -gauge needle, then gently squeezed to extrude a small amount of feces from the perforation sites. In the sham/CLP mice, the cecum was exposed but neither ligated nor punctured. The cecum was then placed back into the peritoneal cavity and the incision was sutured closed in two layers. Mice were resuscitated with $1 \mathrm{ml}$ of Ringers lactate by subcutaneous injection [26].

\section{Cl-Amidine Calculations and Dosing}

Cl-amidine (Cayman Chemical, Ann Arbor, Mich., USA) was reconstituted in EtOH for a stock solution of $20 \mathrm{mg} / \mathrm{ml}$ and kept at $-20^{\circ} \mathrm{C}$. Working solutions were created by diluting $\mathrm{Cl}$-amidine stock solution with PBS to a concentration of $2.0 \mathrm{mg} / \mathrm{ml}$. Mice in the $\mathrm{Cl}$-amidine treatment groups were given doses of $50 \mathrm{mg} / \mathrm{kg}$ $[27,28]$ subcutaneously, $30-60 \mathrm{~min}$ prior to CLP (control animals received $\mathrm{PBS})$.

\section{Survival Study}

Both Cl-amidine-treated and control mice ( $\mathrm{n}=12$ /group) were subjected to CLP, and received additional doses once a day for 7 days. Their survival was observed; log-rank statistical analysis was used to determine if a statistically significant difference in septic mortality was evident between the two groups at $\mathrm{p}<0.05$.

\section{Sample Collection}

At 24 or $48 \mathrm{~h}$ after the sham/CLP procedures, the mice were euthanized with a $\mathrm{CO}_{2}$ overdose. Blood was collected in a heparinized tube via cardiac puncture and centrifuged to obtain plasma. To collect peritoneal fluid for Western blot and cytokine analysis, $1 \mathrm{ml}$ of $1 \times$ PBS was injected intraperitoneally, recollected, and centrifuged at $10,000 \mathrm{~g}$ for $10 \mathrm{~min}$. The supernatant was collected. For the collection of peritoneal cells, $5 \mathrm{ml}$ of $1 \times \mathrm{PBS}$ was injected and recollected via IP, and centrifuged at $10,000 \mathrm{~g}$ for $10 \mathrm{~min}$. The cell pellet was collected for NET analysis and morphological analysis. For Western blot analysis, cell pellets were lysed and spun down again at $10,000 \mathrm{~g}$ for $10 \mathrm{~min}$ and lysate was collected. The lung, liver, spleen, and kidney were also harvested for cytokine analysis. The protein concentration in lavage fluid and cell/tissue lysate was assessed by Bradford assay. All of the samples collected were stored at $-80^{\circ} \mathrm{C}$ until needed.

\section{H3cit Protein Modification}

Samples were probed for H3cit via Western blot. Proteins (25 $\mu \mathrm{g}$ per lane) were separated by $16 \%$ SDS-page gels and transferred on to polyvinylidene fluoride membranes (Novex, San Diego, Calif., USA). The membranes were blocked with 5\% milk in PBST and 


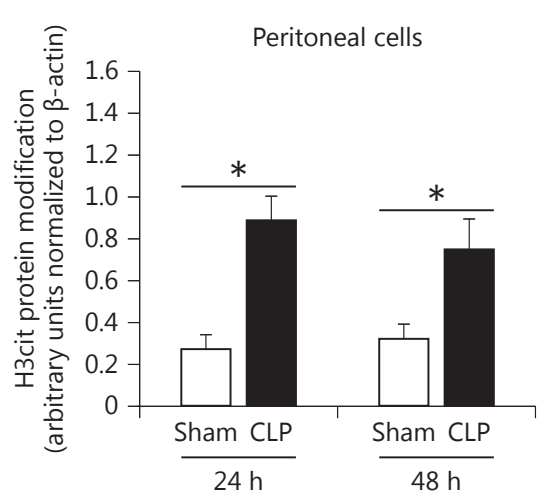

a

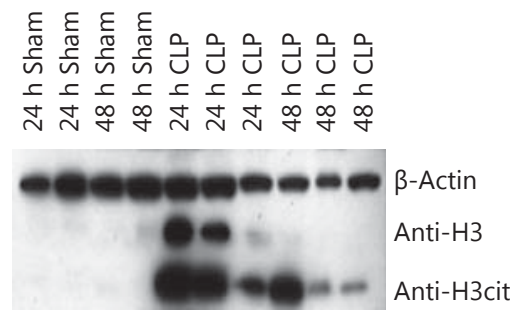

b

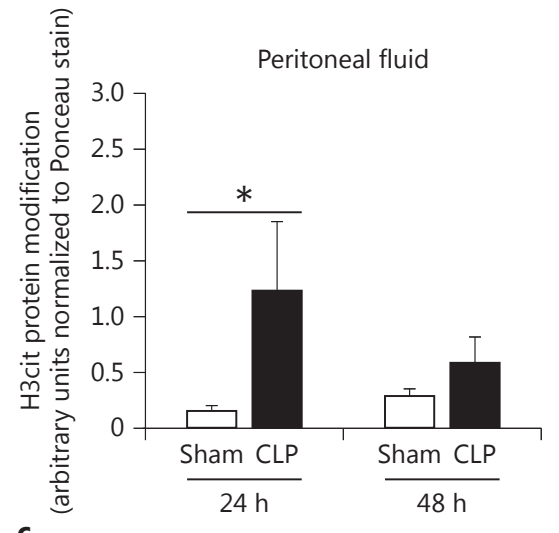

c

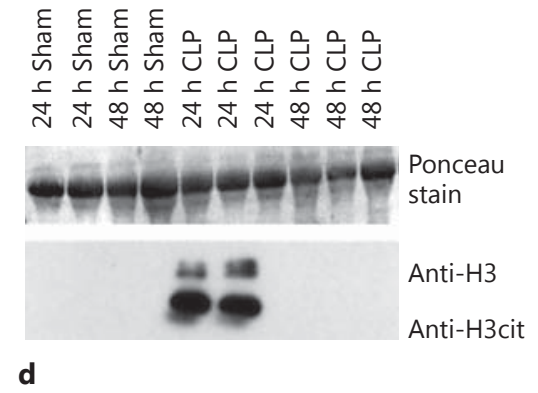

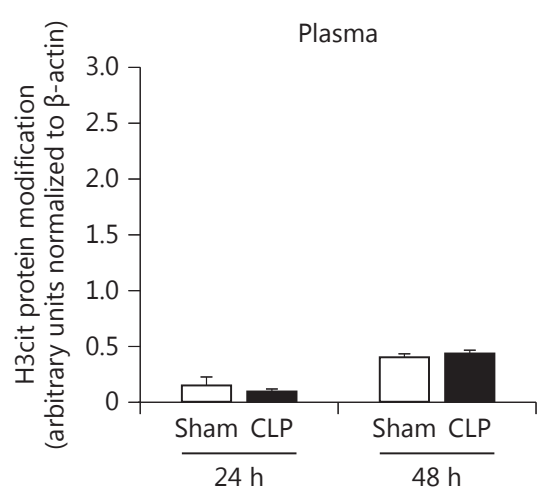

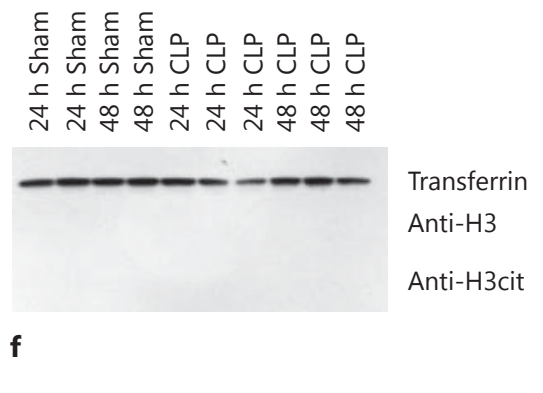

Fig. 1. H3cit protein modification is present after CLP. a, b The $\mathrm{H} 3$ cit protein modification is highly abundant in cells collected from the peritoneal cell lysates collected $24 \mathrm{~h}$ after CLP. At $48 \mathrm{~h}$ after CLP there is still an increase in $\mathrm{H} 3$ cit protein modification. c, d Fluid collected from the peritoneal cavity is also increased in $\mathrm{H} 3$ cit protein modification at $24 \mathrm{~h}$ after CLP, while levels decrease

probed with anti-histone $\mathrm{H} 3$ (citrulline $\mathrm{R} 2+\mathrm{R} 8+\mathrm{R} 17$; ab5103) or anti-histone H3 (ab8898; Abcam, Cambridge, Mass., USA) at $1 \mu \mathrm{g} /$ ml overnight at $4^{\circ} \mathrm{C}$ and subsequently incubated with a HRP-conjugated anti-rabbit $\operatorname{IgG}(1: 10,000)$ at room temperature for $1 \mathrm{~h}$. Chemiluminescence detection was performed using ECL reagent (GE Healthcare, Pittsburgh, Pa., USA), and films were developed using the standard procedure. The abundance of modified histone $\mathrm{H} 3$ protein was densitometrically assessed on an Alpha-Innotech image analyzer (San Leandro, Calif., USA) [29]. H3cit protein was then normalized to either $\beta$-actin for the cell lysates or to the Ponceau-stained membrane for secretory proteins in peritoneal fluid [30].

\section{Measurement of Cytokines}

Concentrations of interleukin (IL)- 6 and IL-10 from the peritoneal fluid, plasma, and tissue samples were assessed via ELISA according to manufacturer's protocols (BD Bioscience) [31]. after 48 h. e, f At both time points, the $\mathrm{H} 3$ cit protein modification was undetectable in the bloodstream. H3cit protein was then normalized to either $\beta$-actin for the cell lysates or to the Ponceaustained membrane that demonstrated equal loading in the peritoneal fluid. Sham, $\mathrm{n}=4$; CLP, $\mathrm{n}=5-6$ per group. ${ }^{*} \mathrm{p}<0.05$, one-way ANOVA.

\section{NET Visualization/Flow Cytometry}

Cells collected from peritoneal lavage were resuspended (1:20) in $1 \times$ PBS and placed on tissue culture plates coated with $1 \%$ BSA and incubated at $37^{\circ} \mathrm{C}$ for $1-2 \mathrm{~h}$. A total of $5 \mu \mathrm{M}$ of Sytox green (Thermo Fischer Scientific, Waltham, Mass., USA) was added 10 min prior to imaging. The images were captured using a Nikon TE-2000U inverted microscope (Nikon, Melville, N.Y., USA) coupled to an iXon ${ }^{\mathrm{EM}}+897 \mathrm{E}$ back illuminated EMCCD camera (Andor, Belfast, UK). Bright field images were captured using NIS-Elements software (Nikon). A xenon lamp illuminated cells through a 33-mm ND4 filter and 20× Nikon Plan Apochromat objective using a Nikon B2-A long-pass emission filter set cube.

For flow cytometry, all the antibodies used for analysis were purchased from eBioscience (San Diego, Calif., USA). $\mathrm{LY} 6 \mathrm{G}^{+}$cell populations in the peritoneal lavage were determined with a FACS Array flow cytometer (BD Bioscience, San Jose, Calif., USA) and analyzed with FlowJo software (Tree Star, Ashland, Oreg., USA) [31]. 
Fig. 2. H3cit protein modification is significantly diminished in the peritoneal cavity in mice treated with $\mathrm{Cl}$-amidine $24 \mathrm{~h}$ after CLP. Mice were either treated with Cl-amidine given at $50 \mathrm{mg} / \mathrm{kg}$ by subcutaneous injection or vehicle control $(1 \times$ PBS $) 30-60$ min prior to CLP. Peritoneal cell lysates and peritoneal fluid were then collected from both groups of mice $24 \mathrm{~h}$ after CLP. a, $\mathbf{b}$ The abundance of $\mathrm{H} 3$ cit protein modification was significantly diminished in the peritoneal cell lysates collected from treated mice as compared to vehicle control mice. c, d The levels of $\mathrm{H} 3$ cit protein were also significantly diminished in peritoneal fluid after treatment. Overall, treatment with $\mathrm{Cl}$-amidine did not fully eliminate the $\mathrm{H} 3$ cit protein modification in every treated animal; however, there was still a consistent reduction in comparison to the vehicle-treated mice. H3cit protein was then normalized to either $\beta$-actin for the cell lysates or a nonspecific $64-\mathrm{kD}$ band located on the Ponceau-stained membrane that demonstrated equal loading in the peritoneal fluid gels. Sham, $\mathrm{n}=4$; CLP, $\mathrm{n}=6-8$ per group. ${ }^{*} \mathrm{p}<0.05$ sham versus CLP, ${ }^{*} \mathrm{p}$ $<0.05$ CLP vehicle versus CLP Cl-amidine, one-way ANOVA.
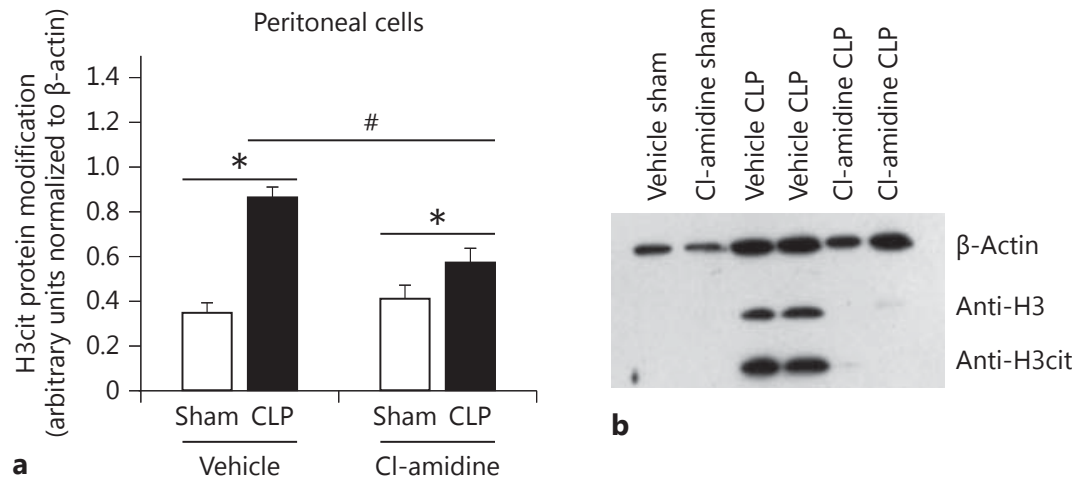

b
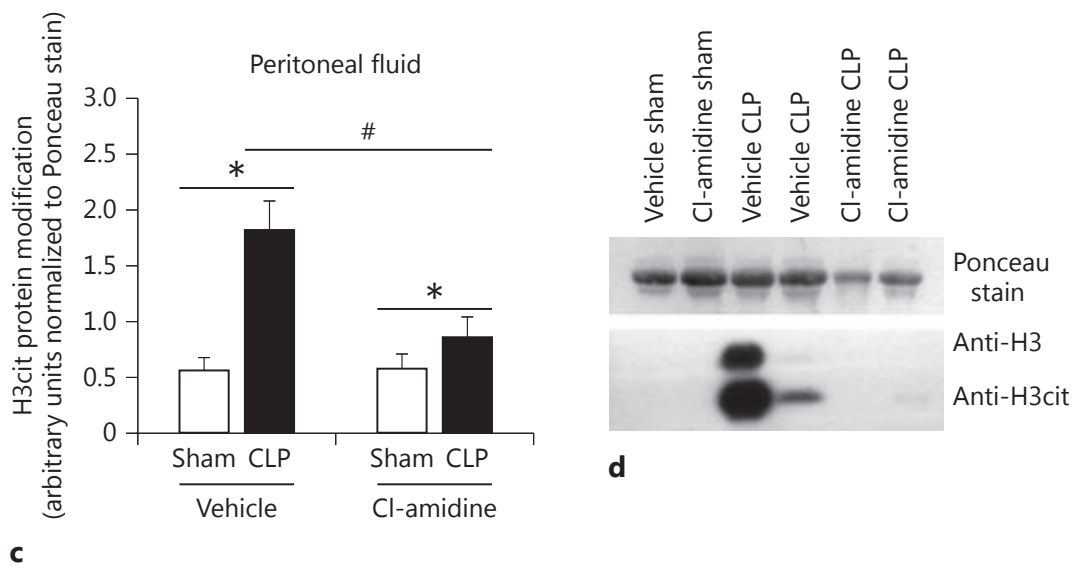

\section{NET Quantification}

Neutrophils were prepared as described above for NET visualization/flow cytometry. NETs were visualized with Sytox green and multiple images were obtained per well. Images were thresholded using the default thresholding algorithm in Image $(\mathrm{NIH}$, Bethesda, Md., USA) and gated to include extruded NETs and exclude stained nuclei. NET formation was quantified as the percent area of the totaled imaged field. Well averages were then ensemble averaged. Data represent 4-6 wells per condition.

\section{Statistics}

Results are expressed as the mean \pm SEM. The statistical significance of the results presented were determined by one-way ANOVA (for multiple comparison) with all pairwise multiple comparison procedures (the Holm-Sidak or Dunn's method), unpaired two-tailed Student's t test (for normal distribution data), or log-rank test (for survival study) where appropriate. The statistical software used was SigmaPlot 11.0 (Systat Software Inc., San Jose, Calif., USA), and $\mathrm{p} \leq 0.05$ was used as a cutoff for significance. For NET quantification ANOVA analysis with Newman-Keuls post hoc analysis or unpaired-sample two-tailed Student's t test as appropriate was performed using MATLAB (Mathworks, Natick,
Mass., USA) or Excel (Microsoft, Redmond, Wash., USA) running the statistiXL data package (statistiXL, Nedlands, W.A., Australia). The null hypothesis was rejected at $\mathrm{p}<0.05$.

\section{Results}

\section{Citrullination of Histone H3 Is Increased $24 \mathrm{~h}$ after CLP}

Histone $\mathrm{H} 3$ citrullination has been used as a marker for PAD4 activity and NET formation [10, 17]. First, we wanted to determine if $\mathrm{H} 3$ cit protein modification was evident in our CLP model of sepsis. The abundance of H3cit protein modification was measured in plasma, peritoneal fluid, and peritoneal cells 24 and $48 \mathrm{~h}$ after CLP via Western blot assay. Histone $\mathrm{H} 3$ was also measured in whole cell lysates and peritoneal fluid. To further ensure that $\mathrm{H} 3 \mathrm{cit}$ modification was independent of histone $\mathrm{H} 3$, we blotted for histone $\mathrm{H} 3$ as well as $\mathrm{H} 3$ cit in 


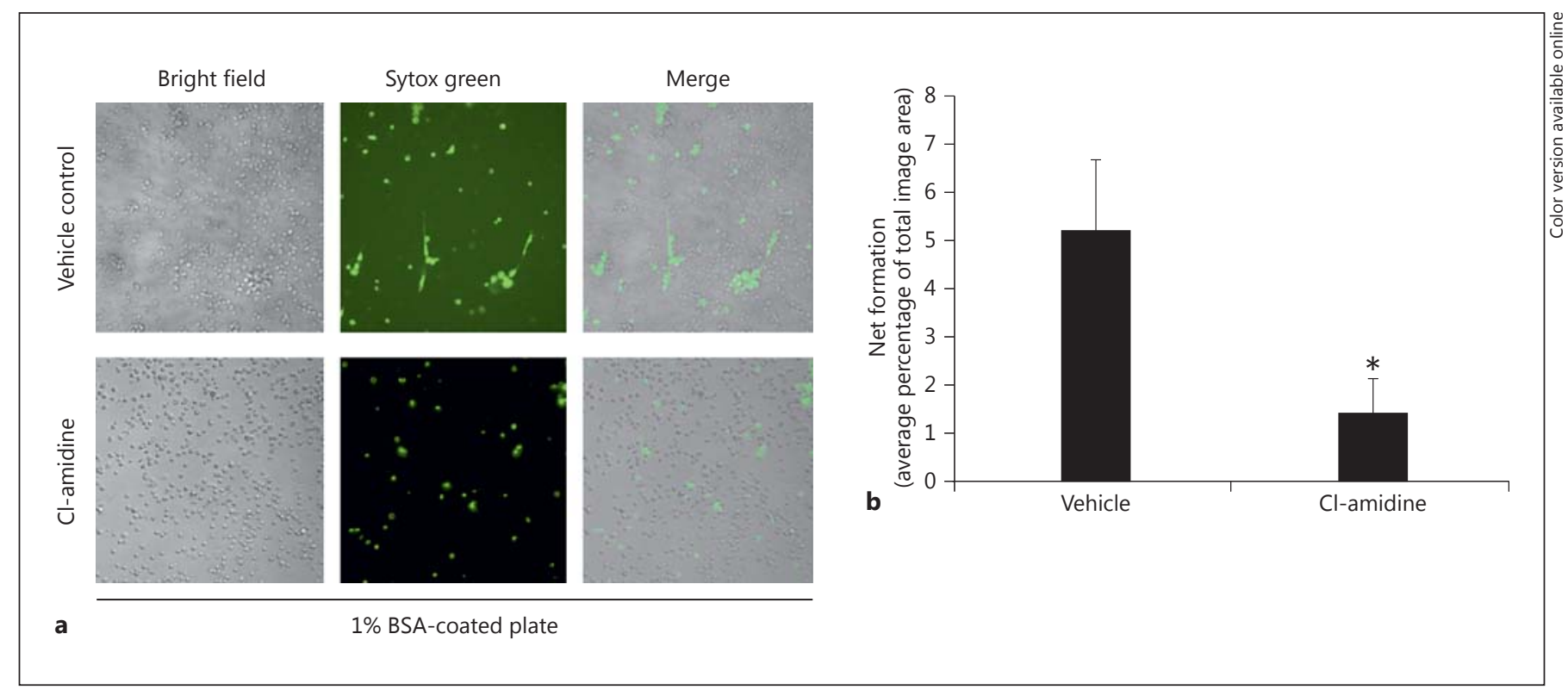

Fig. 3. Cl-amidine treatment in vivo reduces NET formation in murine neutrophils ex vivo. Septic mouse lavage contents were placed on tissue culture plates coated with $1 \%$ BSA (with no additional stimulation) incubated at $37^{\circ} \mathrm{C}$ for $1-2 \mathrm{~h}$, and stained with Sytox green for extracellular nucleic acid visualization. a Peritoneal cells from $\mathrm{Cl}$-amidine-treated mice display a decrease in extracellular nuclear material (NET formation) compared to control cells at $1-2 \mathrm{~h}$. Original magnification $\times 20$. $\mathbf{b}$ This reduction in NET formation is statistically significant when quantified as the percent area of the totaled imaged field. (Data represent 4-6 wells per condition.) ${ }^{*} \mathrm{p}<0.05$, ANOVA analysis with Newman-Keuls post hoc analysis or unpaired-sample two-tailed Student's t test as appropriate. nuclear protein isolated from peritoneal cells and determined that $\mathrm{H} 3$ cit levels were separate from histone $\mathrm{H} 3$ levels (online suppl. fig. 1; for all online suppl. material, see www.karger.com/doi/10.1159/000448808). At $24 \mathrm{~h}$ after CLP, H3cit protein abundance was significantly elevated in the peritoneal cells (fig. $1 \mathrm{a}, \mathrm{b}$ ) as well as in peritoneal fluid (fig. 1c, d) when compared to sham mice; however, H3cit was not detected in the plasma of sham or CLP mice (fig. 1e, f). At $48 \mathrm{~h}$ after CLP, a significant increase of $\mathrm{H} 3$ cit was still detected in peritoneal cell lysates; however, H3cit was no longer present in the peritoneal fluid. Therefore, a 24-hour time point was chosen for later experiments.

\section{Cl-Amidine Reduces the Abundance of the \\ H3cit Protein Modification in Peritoneal Fluid and \\ Peritoneal Cells after CLP}

We wanted to determine whether inhibition of PAD4 activity would eliminate or significantly decrease $\mathrm{H} 3$ cit protein modification in mice subjected to CLP. Cl-amidine was administered at a dose of $50 \mathrm{mg} / \mathrm{kg}$ given subcutaneously 30-60 min prior to CLP. Overall, in vivo Clamidine treatment significantly reduced $\mathrm{H} 3$ cit protein modification at $24 \mathrm{~h}$ after CLP in peritoneal cells (fig. 2a, b) as well as in peritoneal fluid (fig. 2c, d). While elimination of an H3cit protein band was not seen in every treated animal, there was still a consistent reduction in comparison to the vehicle-treated mice.

\section{Cl-Amidine Treatment Reduces NET Formation in Peritoneal Cells after CLP}

To support the observation that $\mathrm{Cl}$-amidine treatment reduces the $\mathrm{H} 3$ cit protein modification implicated in NET formation after CLP, the capacity for NET formation by peritoneal neutrophils was assessed ex vivo. Peritoneal content was collected via lavage (which is a compilation of mostly CLP-activated neutrophils, and macrophages) from mice $24 \mathrm{~h}$ after CLP. Peritoneal cells were cultured on BSA-coated plates with no ex vivo stimulation and stained with Sytox green for extracellular nucleic acid visualization, which has been used to identify NET formation in stimulated cells [32]. After 1-2 h of incubation, there was a marked reduction of NET formation in mouse cells taken from the $\mathrm{Cl}$-amidine-treated mice as compared to the vehicle-treated CLP mice (fig. 3a, b). 


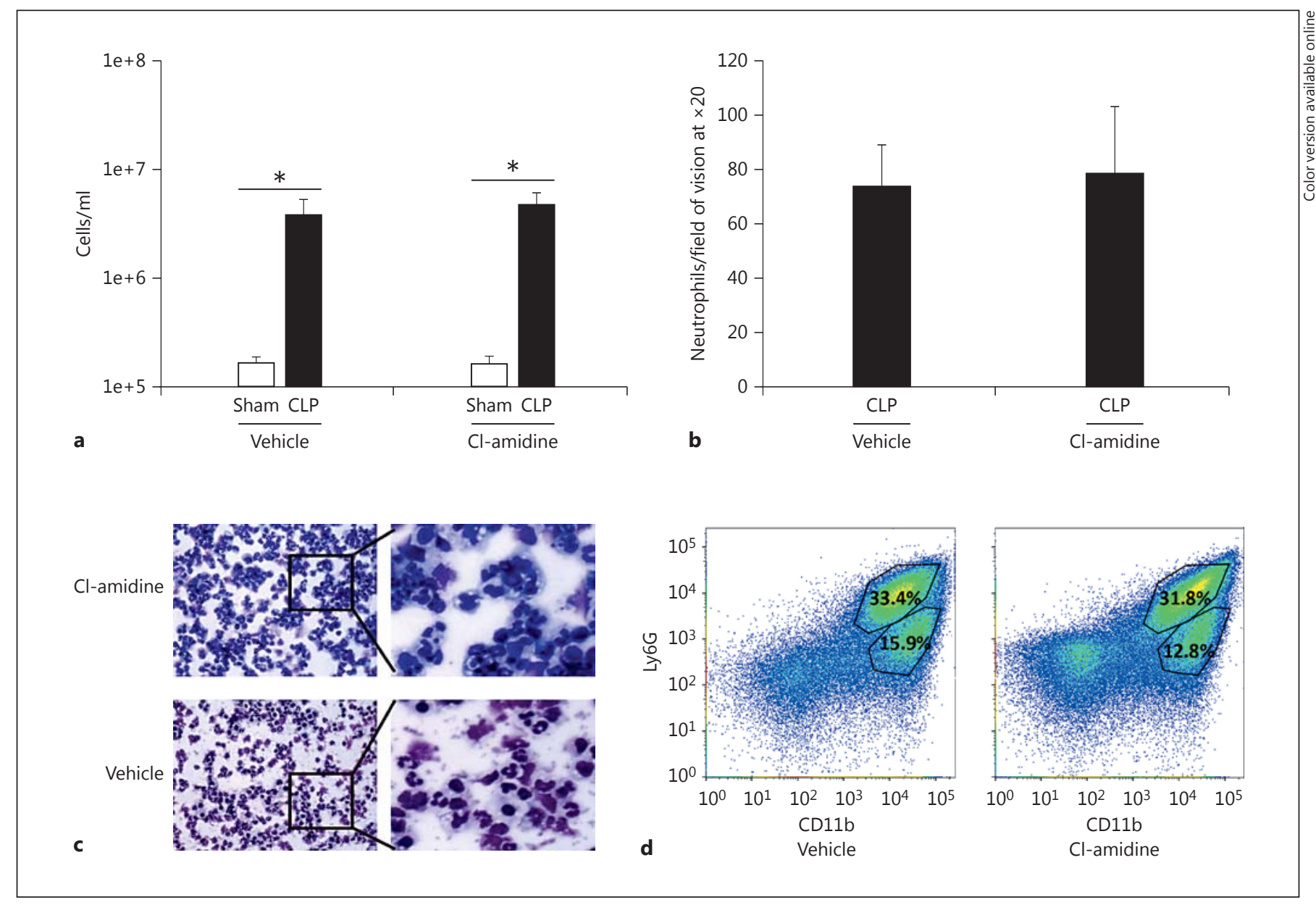

Fig. 4. Cl-amidine treatment has no effect on neutrophil migration to the peritoneum after CLP. Cells were collected from the peritoneum by injecting $5 \mathrm{ml}$ of $1 \times \mathrm{PBS}$ into the abdomen and then harvesting an equal volume. a The total number of cells as determined by a hemocytometer was not different between the Cl-amidineand vehicle-treated groups. b, c Cytospins of peritoneal cells were Wright-stained and analyzed for neutrophil counts at $\times 20$ magni-

\section{Cl-Amidine Treatment Does Not Alter Neutrophil}

Recruitment to the Peritoneum after CLP

To determine whether the reduction of $\mathrm{H} 3$ cit protein modification in the peritoneal cavity was due to PAD4 inhibition, as opposed to a possible off-target effect of Clamidine that may hamper neutrophil migration to the site of infection, we compared the number of neutrophils in the peritoneal cavity in the $\mathrm{Cl}$-amidine-treated and vehicle-treated groups after CLP. Cell numbers were significantly increased in both treated groups subjected to CLP as compared to sham animals (fig. 4a). However, there was no difference in cell numbers between the $\mathrm{Cl}$-amidine and vehicle-treated CLP groups. As the peritoneum after CLP fication using an RGB, DIC N1 filter $(0.33 \mu \mathrm{m} /$ pixel). The number of neutrophils did not significantly differ between the vehicle control and the $\mathrm{Cl}$-amidine-treated animals. $\mathbf{d}$ The percentage of Ly $6 \mathrm{G}^{+}$cells in the peritoneum in both groups at $24 \mathrm{~h}$ after CLP demonstrated no significant difference between the vehicle- and CL-amidine-treated animals, consistent with neutrophil counts. Sham, $\mathrm{n}=4$; CLP, $\mathrm{n}=12$ per group. ${ }^{*} \mathrm{p}<0.05$, one-way ANOVA. 


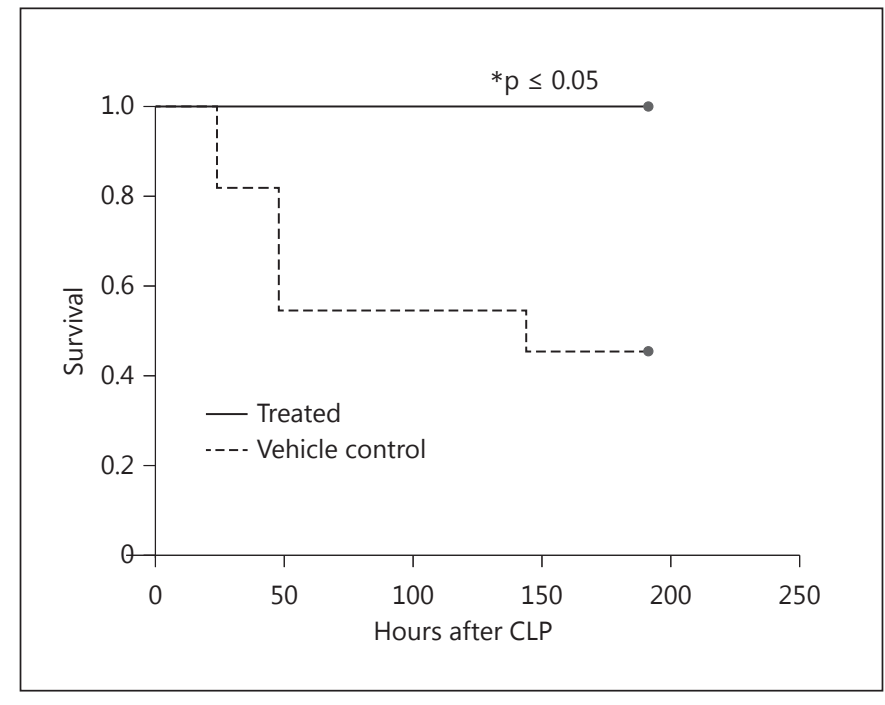

Fig. 5. Cl-amidine treatment improves survival in the CLP sepsis model. Mice were divided into randomized groups and treated with a $50 \mathrm{mg} / \mathrm{kg}$ dose of $\mathrm{Cl}$-amidine or $1 \times \mathrm{PBS}$ (vehicle control) by subcutaneous injection 30-60 min prior to CLP and then once a day for 7 days after the procedure. The $\mathrm{Cl}$-amidine-treated group had a $100 \%$ survival rate compared to the control group, which had a $45 \%$ survival rate. Sham animals had a $100 \%$ survival rate (data not shown). Sham, $\mathrm{n}=3$; CLP, $\mathrm{n}=12$ per group. ${ }^{*} \mathrm{p}<0.05$, logrank test.

\section{Cl-Amidine Treatment Improves Survival in the CLP Sepsis Model}

Extracellular histones as well as circulating free DNA (cf-DNA) have been implicated in increased organ injury and mortality in the CLP model $[8,11]$. To better understand the role of PAD4 in sepsis mortality, we performed CLP in two groups: the first group was treated with $\mathrm{Cl}-$ amidine 30-60 min prior to the procedure, and the second with vehicle control. Mice were then given subsequent doses of $\mathrm{Cl}$-amidine or vehicle, respectively, every day for 7 days. We observed that the $\mathrm{Cl}$-amidine-treated animals were significantly protected from CLP-induced mortality, with a $100 \%$ survival rate at 7 days, as compared to the vehicle-treated group which had a $45 \%$ survival rate (fig. 5). Animals undergoing sham surgery had a $100 \%$ survival rate.

\section{Cl-Amidine Treatment Leads to a Minimally \\ Decreased Proinflammatory Response}

To further investigate how Cl-amidine increases survival, we measured alterations in the proinflammatory cytokine IL- 6 as well as anti-inflammatory cytokine IL-10 in tissues known to be affected by sepsis [37-39], in the plasma, and in peritoneal fluid [40]. Extracellular his-
Fig. 6. Cl-amidine treatment significantly alters proinflammatory IL-6 cytokine levels in the spleen after CLP, but not in other tissues. Tissue homogenate lysates were normalized using a Bradford protein assay and were then assessed for IL- 6 levels by ELISA. The tissues assessed were kidney (a), lung (b), spleen (c), and (d) liver $24 \mathrm{~h}$ after CLP. IL-6 levels were not significantly altered between the vehicle control and Clamidine-treated mice in all tissues except in the spleen, where $\mathrm{Cl}$-amidine treatment significantly reduced IL-6 levels as compared to vehicle control CLP mice. Sham, $\mathrm{n}=6$; CLP, $\mathrm{n}=12-16$ per group. ${ }^{*} \mathrm{p}<0.05$ sham versus CLP, ${ }^{\#} \mathrm{p}<0.05$ CLP vehicle versus CLP Cl-amidine, one-way ANOVA.

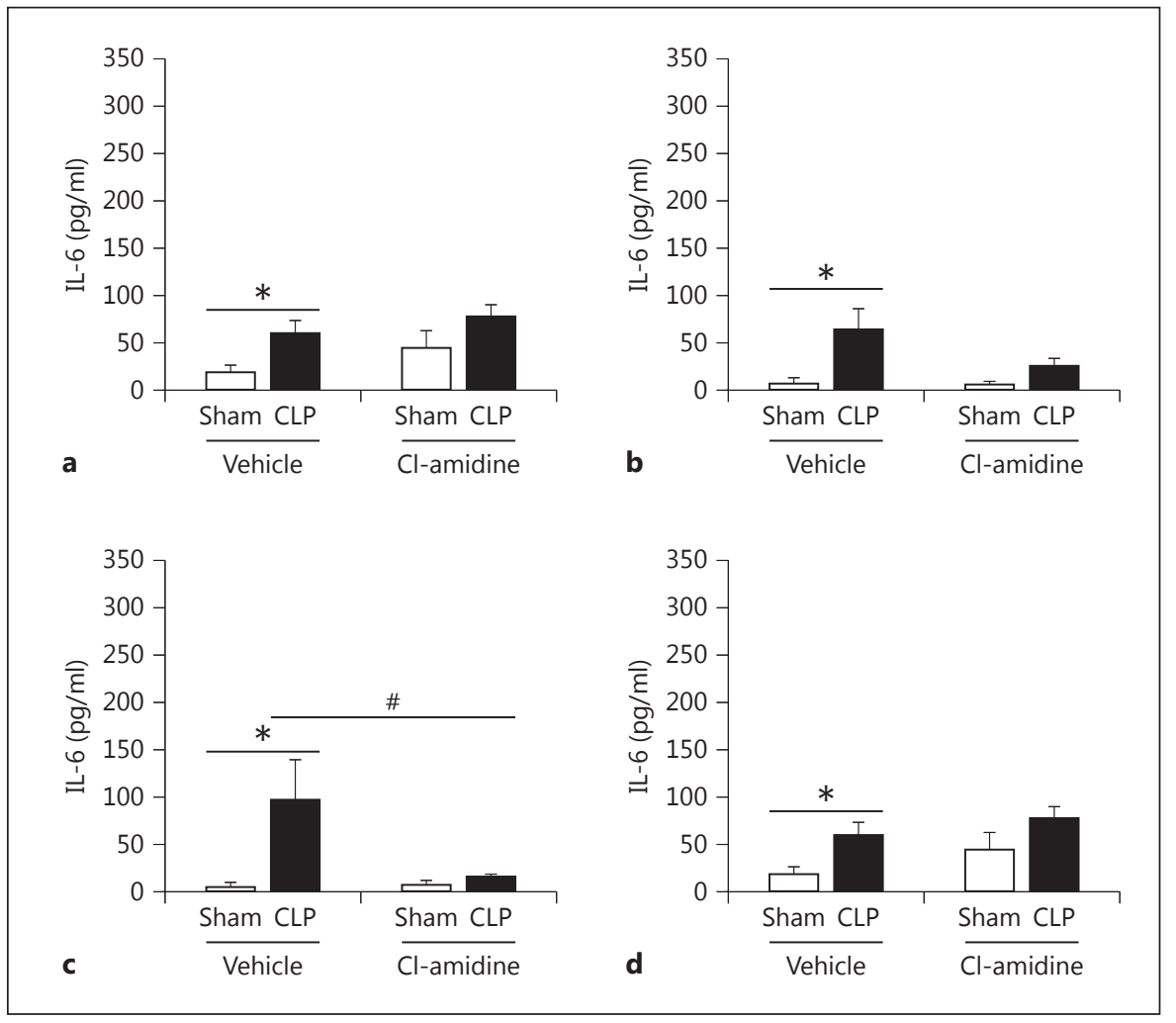


tones and NETs have been attributed to causing excessive inflammation [12, 41, 42]. Here we found that there was a significant, marked reduction of IL-6 in the spleen. However, there was no significant reduction of IL-6 in the kidney, lung, and liver tissues (fig. 6). This may be attributed to the increase of other cell types, such as macrophages, which also secrete IL- 6 after CLP as part of the initial innate immune response to infection [36]. In addition, there was also no difference in IL-10 levels found in tissues (fig. 7). When looking systemically (plasma) and at the site of infection (peritoneal fluid) there was no reduction of IL-6, but there was a significant increase of IL10 levels in the bloodstream in the $\mathrm{Cl}$-amidine-treated mice as compared to both the sham and vehicle control CLP mice (fig. 8).

\section{Discussion}

NETs are complex structures comprised of nuclear chromatin, histones, granular antimicrobial proteins, and cytoplasmic proteins [7]. While NET formation physically ensnares bacteria and facilitates the interactions between bacteria and antimicrobial effectors, ulti- mately leading to enhanced bacterial killing, they also contribute to detrimental effects such as excessive inflammation and tissue damage in the host $[6,11,12]$.

PAD4 activity is an important component of neutrophil activation, NET formation, and the innate immune response $[10,13]$. Alternatively, PAD4 activity and histone citrullination has also been shown to be a contributor to various autoimmune diseases, such as rheumatoid arthritis, lupus, and IBD, and serves as a convergence point for many inflammatory signals that prompt the response of neutrophils to infections [27, 41-43]. In the case of sepsis, these extracellular histones have been linked to tissue damage as well as increased mortality [11]. PAD4 gene deletion studies have been variable. PAD4 ${ }^{-/-}$mice have been shown to be susceptible to bacterial infections and their neutrophils display a significant reduction in bacterial killing in vitro [10]. However, when additional in vivo studies of sepsis utilizing these $\mathrm{PAD}^{-/-}$mice using the CLP model were performed, PAD4 gene deletion appeared to have no real effect on survival [19]. This discrepancy in survival results as compared to our findings may be attributed to the differences in the model procedure as well as differences in control mortality rates. Moreover, PAD inhibition as compared
Fig. 7. Cl-amidine treatment does not significantly alter anti-inflammatory IL-10 cytokine levels in tissues. The same tissue homogenate lysates used for IL-6 level assessment were also assessed for IL-10 levels as a measurement of alteration in the antiinflammatory response. The tissues assessed were kidney (a), lung (b), spleen (c), and liver (d) $24 \mathrm{~h}$ after CLP. There was a significant increase in IL-10 levels in the kidneys in both the vehicle and $\mathrm{Cl}$-amidine CLP groups compared to shams. However, IL-10 levels were not significantly different between the vehicle control and $\mathrm{Cl}$-amidine-treated mice in all tissues. Sham, $\mathrm{n}=$ 6; CLP, $\mathrm{n}=12-16$ per group. ${ }^{*} \mathrm{p}<0.05$ sham versus CLP, one-way ANOVA.

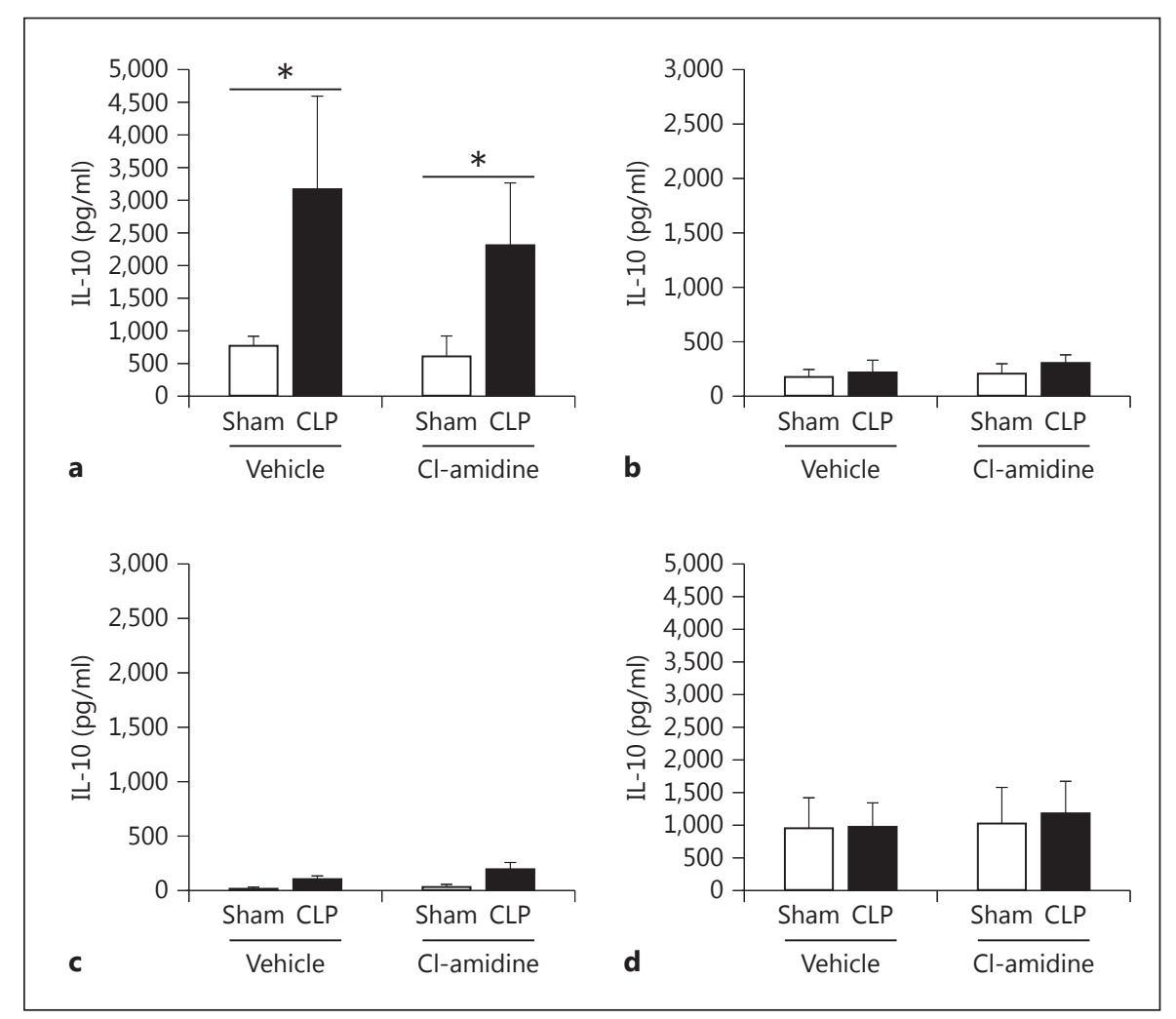


Fig. 8. Cl-amidine treatment increases systemic levels of IL-10 but has no impact on the systemic proinflammatory response after CLP. Plasma was collected from heparinized whole blood via cardiac puncture, and peritoneal fluid was collected from the abdomen by injecting $1 \mathrm{ml}$ of $1 \times$ PBS intraperitoneally and then recollected. Both samples were analyzed for IL- 6 and IL-10 levels. a, b IL-6 levels were significantly increased in the plasma and peritoneal fluid of both the vehicle and $\mathrm{Cl}$-amidine-treated groups after CLP. c Systemically, IL-10 levels were significantly increased in the Clamidine-treated mice as compared to the vehicle control mice after CLP. d IL-10 levels were comparable in both groups at the site of infection in the peritoneum. Sham, $\mathrm{n}=6$; CLP, $\mathrm{n}=12-16$ per group. ${ }^{*} \mathrm{p}<0.05$, ${ }^{* *} \mathrm{p}<0.01$ sham versus CLP, ${ }^{*} \mathrm{p}<0.05$ CLP vehicle versus CLP Cl-amidine, one-way ANOVA.

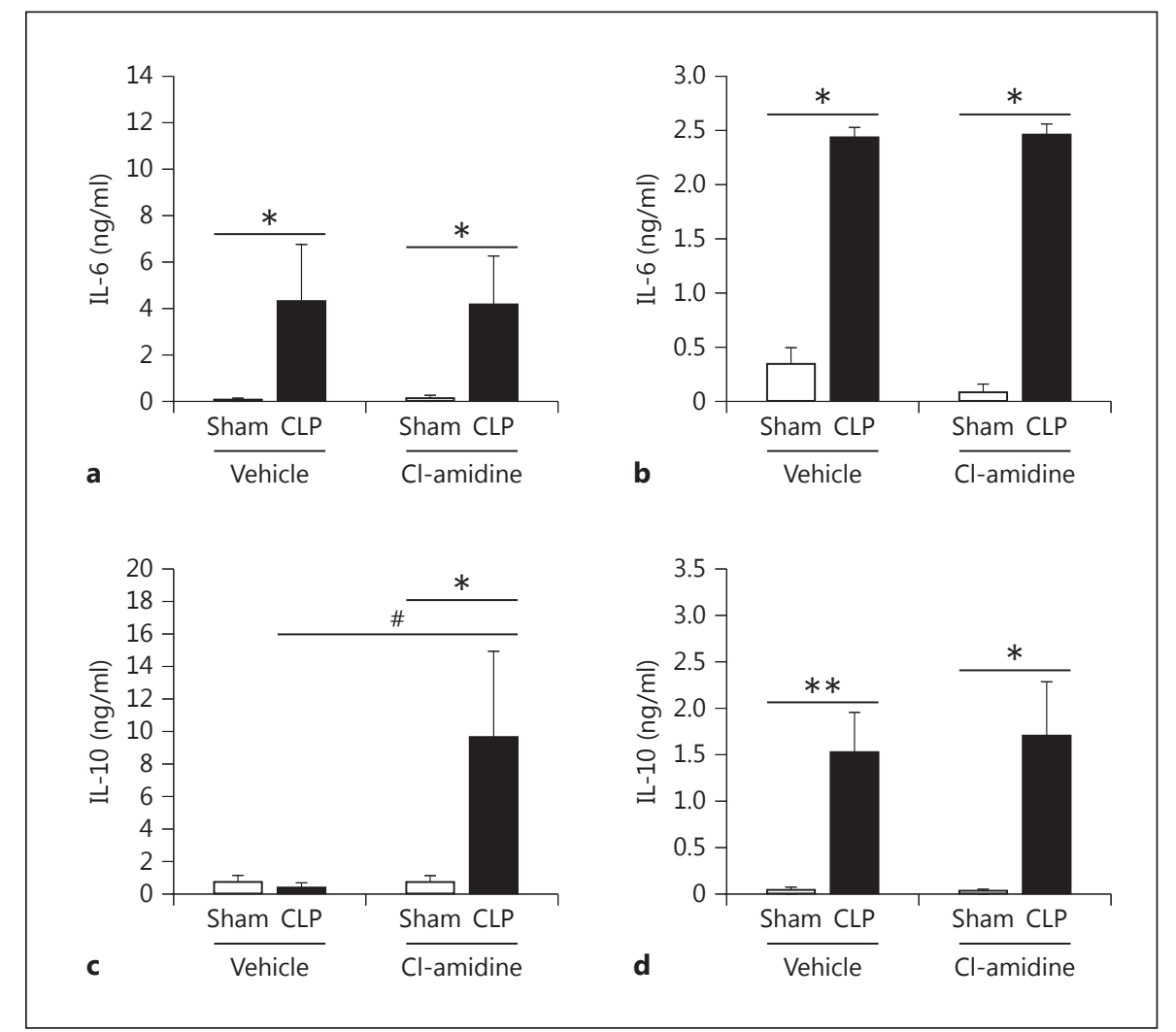

to PAD4 gene deletion may also account for the differences as the use of $\mathrm{Cl}$-amidine or neutralization of circulating citrullinated histones using anti-H3cit antibody as a therapeutic strategy has been shown to increase survival in septic mice [44]. Our results confirm this increase in survival in the CLP model using a different dosing strategy, which included a smaller subcutaneous dose of $\mathrm{Cl}$ amidine given prior to CLP. Thus, this demonstrates that chemical inhibition of PADs, and subsequently histone citrullination and NET formation, leads to increased survival against septic insult. Protein expression analysis demonstrated that the PAD inhibitor, $\mathrm{Cl}$-amidine, did not fully negate all histone citrullination, but greatly suppresses it as compared to vehicle-treated CLP mice. Furthermore, the reduction of $\mathrm{H} 3$ cit protein modification after $\mathrm{Cl}$-amidine treatment is likely due to PAD4 inhibition and not a reduction of neutrophils emigrating into the site of infection.

With extracellular cf-DNA and citrullinated histones having been reported to be detected within the bloodstream during a septic infection $[19,45]$ and circulating $\mathrm{H} 3 \mathrm{cit}$ reported as a potential biomarker for the early diagnosis of septic shock [9], H3cit has been proposed as a target considered for improving survival in the CLP model [44]. In our model we were unable to detect $\mathrm{H} 3$ cit within the bloodstream using protein expression by Western immunoblot as our method of detection at 24 or $48 \mathrm{~h}$ after CLP. Furthermore, others have suggested that the elevated cf-DNA levels reported during the early phase are not derived from neutrophils or NETs, but from other factors such as necrotic tissue or apoptotic cells [46]. The $\mathrm{H} 3$ cit protein modification was detected in the peritoneal cavity after CLP. As neutrophils are one of the first immune cells to respond to infection [47], it is possible that the increase in citrullination is due to PAD4 activity. Collectively, our data suggest that NETosis is occurring within the peritoneum $24 \mathrm{~h}$ after CLP $[11,16,17]$ and that the $\mathrm{H} 3$ cit protein modification, and by extension NET formation, is reduced in the peritoneal cavity with $\mathrm{Cl}$-amidine treatment.

$\mathrm{Cl}$-amidine treatment has been demonstrated to improve various inflammatory disease phenotypes in autoimmune disorders $[27,28,43]$. Interestingly, $\mathrm{Cl}$-amidine treatment has also been shown to have an effect on dendritic cell maturation induced by TLR agonists to reduce proinflammatory cytokine levels as well as impair the 
proliferation of naïve $\mathrm{CD} 4^{+}$and $\mathrm{CD} 8^{+} \mathrm{T}$ cells both in vitro and in vivo [48]. A reduction in proinflammatory markers was also seen in our study where there was a reduction in IL-6 levels in the spleen after CLP. These data, taken together, suggest that $\mathrm{Cl}$-amidine treatment may have a hand in reducing inflammation that is caused by extracellular histones and NETs. Surprisingly, IL-10 levels were significantly increased in the bloodstream in the Cl-amidine-treated mice compared to vehicle-treated mice after $\mathrm{CLP}$, indicating that $\mathrm{Cl}$-amidine treatment may be having an effect on the systemic anti-inflammatory response after CLP. However, IL-10 levels were not significantly affected by Cl-amidine treatment in the peritoneal cavity or in the various organ tissues analyzed. Therefore, it is unclear if PAD4 inhibition has any type of effect on the compensatory anti-inflammatory response that occurs concomitantly with the proinflammatory response [49]. In our model we cannot say definitively that these alterations in pro- and anti-inflammatory signaling are a direct result of NET inhibition, as $\mathrm{Cl}$-amidine is a nonselective PAD inhibitor (not specific to PAD4 and NET formation alone). It would be interesting to further explore the effect of a selective inhibitor of PAD4 on the inflammatory response as it becomes available.

Overall, the results here demonstrate that histone $\mathrm{H} 3$ citrullination is present in the peritoneal cavity as well as within cells collected from the site of infection $24 \mathrm{~h}$ after being subjected to the CLP procedure. This citrullination is modulated when mice are treated with the PAD inhibitor $\mathrm{Cl}$-amidine. Daily treatment significantly improved survival after CLP, suggesting that chemical inhibition of PAD4 is beneficial against polymicrobial septic mortality. Treatment did not affect overall neutrophil emigration into the site of infection. Nonetheless, $\mathrm{Cl}$-amidine did diminish the ability of activated neutrophils to release NETs. While $\mathrm{Cl}$-amidine has been implicated in improving inflammation in various autoimmune disease states, its direct mechanism of action is not clear [24, 27, 43]. $\mathrm{Cl}$-amidine does not seem to have a significant impact on proinflammatory markers of infection, but does alter systemic IL-10 levels, thus having a possible effect on the immunosuppressive response in our model. It is possible that the increase in survival is due to secondary effects caused by $\mathrm{Cl}$-amidine, such as an increase in apoptosis of other inflammatory cells, like that seen in a murine colitis model [43]. While PAD4 inhibitors are under development [50], there is still no specific inhibitor available to study the direct correlation between NET inhibition and subsequent host improvement during a septic infection. Our observations suggest that NET inhibition using $\mathrm{Cl}$ amidine should be further explored as a possible therapeutic maneuver against the damaging proinflammatory response seen in polymicrobial sepsis.

\section{Acknowledgements}

This work was funded by NIH R01-GM46354 and R35 GM118097 (A.A.), and GM066194 (J.S.R). The authors would also like to thank Ms. Lauren Watts for her assistance with flow cytometry.

\section{References}

1 Angus DC, van der Poll T: Severe sepsis and septic shock. N Engl J Med 2013;369:840-851.

2 Angus DC, Linde-Zwirble WT, Lidicker J, Clermont G, Carcillo J, Pinsky MR: Epidemiology of severe sepsis in the United States: analysis of incidence, outcome, and associated costs of care. Crit Care Med 2001;29:13031310.

3 Martin GS, Mannino DM, Eaton S, Moss M: The epidemiology of sepsis in the United States from 1979 through 2000. N Engl J Med 2003;348:1546-1554.

4 Gaieski DF, Edwards JM, Kallan MJ, Carr BG: Benchmarking the incidence and mortality of severe sepsis in the United States. Crit Care Med 2013;41:1167-1174.

5 Kochanek KD, Xu J, Murphy SL, Miniño AM, Kung H-C: Deaths: preliminary data for 2009. Natl Vital Stat Rep 2011;59:1-51.
6 Kovach MA, Standiford TJ: The function of neutrophils in sepsis. Curr Opin Infect Dis 2012;25:321-327.

7 Brinkmann V, Reichard U, Goosmann C, Fauler B, Uhlemann Y, Weiss DS, et al: Neutrophil extracellular traps kill bacteria. Science 2004;303:1532-1535.

8 Margraf S, Lögters T, Reipen J, Altrichter J, Scholz M, Windolf J: Neutrophil-derived circulating free DNA (cf-DNA/NETs): a potential prognostic marker for posttraumatic development of inflammatory second hit and sepsis. Shock 2008;30:352-358.

9 Li Y, Liu B, Fukudome EY, Lu J, Chong W, Jin $\mathrm{G}$, et al: Identification of citrullinated histone $\mathrm{H} 3$ as a potential serum protein biomarker in a lethal model of lipopolysaccharide-induced shock. Surgery 2011;150:442-451.
10 Li P, Li M, Lindberg MR, Kennett MJ, Xiong $\mathrm{N}$, Wang Y: PAD4 is essential for antibacterial innate immunity mediated by neutrophil extracellular traps. J Exp Med 2010;207:18531862.

$11 \mathrm{Xu}$ J, Zhang X, Pelayo R, Monestier M, Ammollo CT, Semeraro F, et al: Extracellular histones are major mediators of death in sepsis. Nat Med 2009;15:1318-1321.

12 Fuchs TA, Brill A, Wagner DD: Neutrophil extracellular trap (NET) impact on deep vein thrombosis. Arterioscler Thromb Vasc Biol 2012;32:1777-1783.

13 Leshner M, Wang S, Lewis C, Zheng H, Chen XA, Santy L, et al: PAD4 mediated histone hypercitrullination induces heterochromatin decondensation and chromatin unfolding to form neutrophil extracellular trap-like structures. Front Immunol 2012;3:307. 
14 Jones JE, Causey CP, Knuckley B, Slack-Noyes JL, Thompson PR: Protein arginine deiminase 4 (PAD4): current understanding and future therapeutic potential. Curr Opin Drug Discov Devel 2009;12:616-627.

15 Rohrbach AS, Slade DJ, Thompson PR, Mowen KA: Activation of PAD4 in NET formation. Front Immunol 2012;3:360.

16 Neeli I, Khan SN, Radic M: Histone deimination as a response to inflammatory stimuli in neutrophils. J Immunol 2008;180:1895-1902.

17 Wang Y, Li M, Stadler S, Correll S, Li P, Wang $\mathrm{D}$, et al: Histone hypercitrullination mediates chromatin decondensation and neutrophil extracellular trap formation. J Cell Biol 2009; 184:205-213.

18 Wang Y, Wysocka J, Sayegh J, Lee Y-H, Perlin JR, Leonelli L, et al: Human PAD4 regulates histone arginine methylation levels via demethylimination. Science 2004;306:279-283.

19 Martinod K, Fuchs TA, Zitomersky NL, Wong SL, Demers M, Gallant M, et al: PAD4deficiency does not affect bacteremia in polymicrobial sepsis and ameliorates endotoxemic shock. Blood 2015;125:1948-1956.

20 Seri Y, Shoda H, Suzuki A, Matsumoto I, Sumida T, Fujio K, et al: Peptidylarginine deiminase type 4 deficiency reduced arthritis severity in a glucose-6-phosphate isomeraseinduced arthritis model. Sci Rep 2015;5: 13041 .

21 Hemmers S, Teijaro JR, Arandjelovic S, Mowen KA: PAD4-mediated neutrophil extracellular trap formation is not required for immunity against influenza infection. PLoS One 2011;6:e22043.

22 Martinod K, Demers M, Fuchs TA, Wong SL, Brill A, Gallant M, et al: Neutrophil histone modification by peptidylarginine deiminase 4 is critical for deep vein thrombosis in mice. Proc Natl Acad Sci USA 2013;110:8674-8679.

23 Luo Y, Arita K, Bhatia M, Knuckley B, Lee $\mathrm{Y}-\mathrm{H}$, Stallcup MR, et al: Inhibitors and inactivators of protein arginine deiminase 4: functional and structural characterization. Biochemistry 2006;45:11727-11736.

24 Willis VC, Gizinski AM, Banda NK, Causey $\mathrm{CP}$, Knuckley B, Cordova KN, et al: $\mathrm{N}-\alpha-$ benzoyl-N5-(2-chloro-1-iminoethyl)-L-ornithine amide, a protein arginine deiminase inhibitor, reduces the severity of murine collagen-induced arthritis. J Immunol 2011;186: 4396-4404.

25 Slack JL, Causey CP, Thompson PR: Protein arginine deiminase 4: a target for an epigenetic cancer therapy. Cell Mol Life Sci 2011;68 709-720.

26 Bai J, Tang L, Lomas-Neira J, Chen Y, McLeish KR, Uriarte SM, et al: TAT-SNAP-23 treatment inhibits the priming of neutrophil functions contributing to shock and/or sepsis- induced extra-pulmonary acute lung injury. Innate Immun 2015;21:42-54.

27 Knight JS, Zhao W, Luo W, Subramanian V, O’Dell AA, Yalavarthi S, et al: Peptidylarginine deiminase inhibition is immunomodulatory and vasculoprotective in murine lupus. J Clin Invest 2013;123:2981-2993.

28 Knight JS, Luo W, O’Dell AA, Yalavarthi S, Zhao W, Subramanian V, et al: Peptidylarginine deiminase inhibition reduces vascular damage and modulates innate immune responses in murine models of atherosclerosis. Circ Res 2014;114:947-956.

29 Perl M, Chung C-S, Perl U, Lomas-Neira J, de Paepe M, Cioffi WG, et al: Fas-induced pulmonary apoptosis and inflammation during indirect acute lung injury. Am J Respir Crit Care Med 2007;176:591-601.

30 Romero-Calvo I, Ocón B, Martínez-Moya P, Suárez MD, Zarzuelo A, Martínez-Augustin $\mathrm{O}$, et al: Reversible Ponceau staining as a loading control alternative to actin in Western blots. Anal Biochem 2010;401:318-320.

31 Shubin NJ, Chung CS, Heffernan DS, Irwin LR, Monaghan SF, Ayala A: BTLA expression contributes to septic morbidity and mortality by inducing innate inflammatory cell dysfunction. J Leukoc Biol 2012;92:593-603.

32 Byrd AS, O’Brien XM, Johnson CM, Lavigne LM, Reichner JS: An extracellular matrixbased mechanism of rapid neutrophil extracellular trap formation in response to Candida albicans. J Immunol 2013;190:41364148.

33 Wang Y, Braun OÖ, Zhang S, Norström E, Thorlacius H: Monocytes regulate systemic coagulation and inflammation in abdominal sepsis. Am J Physiol Heart Circ Physiol 2015; 308:H540-H547.

34 Kuethe JW, Midura EF, Rice TC, Caldwell CC: Peritoneal wash contents used to predict mortality in a murine sepsis model. J Surg Res 2015;199:211-219.

35 Heffernan DS, Monaghan SF, Thakkar RK, Tran ML, Chung C-S, Gregory SH, et al: Inflammatory mechanisms in sepsis: elevated invariant natural killer T-cell numbers in mouse and their modulatory effect on macrophage function. Shock 2013;40:122-128.

36 Ayala A, Perrin MM, Kisala JM, Ertel W, Chaudry IH: Polymicrobial sepsis selectively activates peritoneal but not alveolar macrophages to release inflammatory mediators (interleukins- 1 and -6 and tumor necrosis factor). Circ Shock 1992;36:191-199.

37 Dear JW, Yasuda H, Hu X, Hieny S, Yuen PST, Hewitt SM, et al: Sepsis-induced organ failure is mediated by different pathways in the kidney and liver: acute renal failure is dependent on MyD88 but not renal cell apoptosis. Kidney Int 2006;69:832-836.
38 Doi K, Leelahavanichkul A, Yuen PST, Star RA: Animal models of sepsis and sepsis-induced kidney injury. J Clin Invest 2009;119: 2868-2878.

39 Hiramatsu M, Hotchkiss RS, Karl IE, Buchman TG: Cecal ligation and puncture (CLP) induces apoptosis in thymus, spleen, lung, and gut by an endotoxin and TNF-independent pathway. Shock 1997;7:247-253.

40 Hoesel LM, Neff TA, Neff SB, Younger JG, Olle EW, Gao H, et al: Harmful and protective roles of neutrophils in sepsis. Shock 2005;24: 40-47.

41 Raptopoulou A, Sidiropoulos P, Katsouraki M, Boumpas DT: Anti-citrulline antibodies in the diagnosis and prognosis of rheumatoid arthritis: evolving concepts. Crit Rev Clin Lab Sci 2007;44:339-363.

42 Wang S, Wang Y: Peptidylarginine deiminases in citrullination, gene regulation, health and pathogenesis. Biochim Biophys Acta 2013;1829:1126-1135.

43 Chumanevich AA, Causey CP, Knuckley BA, Jones JE, Poudyal D, Chumanevich AP, et al: Suppression of colitis in mice by $\mathrm{Cl}$-amidine: a novel peptidylarginine deiminase inhibitor. Am J Physiol Gastrointest Liver Physiol 2011; 300:G929-G938.

44 Li Y, Liu Z, Liu B, Zhao T, Chong W, Wang $\mathrm{Y}$, et al: Citrullinated histone H3: a novel target for the treatment of sepsis. Surgery 2014; 156:229-234

45 Luo L, Zhang S, Wang Y, Rahman M, Syk I, Zhang E, et al: Proinflammatory role of neutrophil extracellular traps in abdominal sepsis. Am J Physiol Lung Cell Mol Physiol 2014; 307:L586-L596.

46 Hamaguchi S, Akeda Y, Yamamoto N, Seki $\mathrm{M}$, Yamamoto K, Oishi K, et al: Origin of circulating free DNA in sepsis: analysis of the CLP mouse model. Mediators Inflamm 2015; 2015:614518.

47 Segal AW: How neutrophils kill microbes. Annu Rev Immunol 2005;23:197-223.

48 Jang B, Kim HW, Kim J-S, Kim WS, Lee BR, Kim S, et al: Peptidylarginine deiminase inhibition impairs Toll-like receptor agonistinduced functional maturation of dendritic cells, resulting in the loss of T cell-proliferative capacity: a partial mechanism with therapeutic potential in inflammatory settings. J Leukoc Biol 2015;97:351-362.

49 Hotchkiss RS, Monneret G, Payen D: Sepsisinduced immunosuppression: from cellular dysfunctions to immunotherapy. Nat Rev Immunol 2013;13:862-874.

50 Lewis HD, Liddle J, Coote JE, Atkinson SJ, Barker MD, Bax BD, et al: Inhibition of PAD4 activity is sufficient to disrupt mouse and human NET formation. Nat Chem Biol 2015;11: 189-191. 